\title{
Is Mean Platelet Volume Useful for Predicting the Prognosis of COVID-19 Diagnosed Patients?
}

\author{
Ahmet Aktaş ${ }^{1}$, Kemal Sener ${ }^{2}$, Nurettin Yılmaz ${ }^{2}$, Mehmet Tunç${ }^{2}$, Sadiye Yolcu ${ }^{2}$ \\ ${ }^{1}$ Cumhuriyet University Medical Faculty Dept. of Internal Medicine \\ ${ }^{2}$ Adana City Research \& Education Hospital Dept. of Emergency Medicine, Adana/Turkey \\ *Corresponding Author: Ahmet Aktaş M. D.,Cumhuriyet University Medical Faculty Department of \\ Internal Medicine, Sivas/Turkey.
}

\begin{abstract}
Background: COVID-19; It emerged as a viral pneumonia with very high infectivity and infectiousness in December 2019 in Wuhan province of China. Although its pathogenesis is not known as well, it causes severe inflammation and cytokine storm. It shows many symptoms such as fever, sore throat, headache, dyspnea and diarrhea. WBC, platelet, MPV values and indicators such as CRP and procalcitonin have been shown to be related to the severity of inflammation and disease.

Aim: In this study we aimed to research the relationship between the prognonsis of COVID-19 diagnosed patients over and under 65 years and MPV.

Results: We included 16 females, 21 males totally 37 patients in this study. The mean age of the study group was 54.46.MPV, WBC, CRP and procalcitonin levels were not associated with the prognosis and severity of the disease in COVID-19 patients aged 65 and over. Again, there was no statistically significant relationship between MPV, WBC, CRP and procalcitonin levels and prognosis among the patients hospitalized in the intensive care unit and the service. When the patients who were discharged and died, there was no statistically significant difference between MPV,WBC, CRP and procalcitonin levels.

Conclusion: We did not determnie difference in MPV levels, WBC, CRP and procalcitonin levels, mortality and prognosis between COVID-19 positive patients under 65 and over. Further comprehensive studies are required.
\end{abstract}

Keywords: COVID-19, mean platelet volume, prognosis

\section{INTRODUCTION}

On December 31, 2019, the World Health Organization (WHO) China Country Office reported pneumonia cases of unknown etiology in Wuhan, Hubei province, China. On January 7,2020 , the causative agent was identified as a new Coronavirus (2019-nCoV), which has not previously been detected in humans. Later, the name of 2019-nCoV disease was accepted as COVID-19, and the virus was named as SARSCoV-2 due to its similarity to SARS CoV (1).

The shape of the coronaviruses is pleomorphic or spherical and is characterized by crownshaped protrusions of glycoproteins on its surface. Coronavirus genetic material is sensitive to the frequent recombination process, which can lead to new strains by altering virulence. (2). Coronaviruses have 7 subtypes in humans, including 229E, NL63, OC43, HKU1,
Middle East respiratory syndrome (MERS) $\mathrm{CoV}$, severe acute respiratory syndrome (SARS) - $\mathrm{CoV}$, and 2019-new coronavirus (nCoV). It may show symptoms such as colds, pneumonia, bronchiolitis, rhinitis, pharyngitis, sinusitis and rarely diarrhea (3).

In studies conducted, COVID-19disease can be seen due to cytokine storm, lymphopenia, thrombocytopenia, leukopenia (4). Average platelet volume (MPV) is a parameter of complete blood count (CBC) analysis. MPV and WBC counts are used as markers of the inflammatory response. A correlation has been shown between platelet function and activation and MPV. Previous studies have shown that thrombopoietin and numerous inflammatory cytokines such as IL-1, IL-6, and TNFa regulate thrombopoiesis and MPV is a reflection of both proinflammatory and prothrombotic conditions. Large and small-sized circulating platelets have been shown to be used as a distinguishing factor 
for classifying conditions associated with the intensity of systemic inflammation (5). There are also increased cytokines and systemic inflammation in COVID-19 disease. Especially in patients over 60 years old, COVID-19 is much more mortal (6).

According to our knowledge, there is a limited data about MPV levels of COVID-19 patients. In literature. In this study, we aimed to find out whether there is a relation between systemic inflammation and MPV and prognosis in patients over 65 years old and in patients under 65 years old.

\section{MeTHOdS}

After the ethics committe approval, in this retrospective study, we evaluated COVID-19 diagnosed and hospitalised patients between 10.04.2020-15.04.2020. The diagnosis is made via oro-nasopharengeal swab PCR test. We noted the demographic data (age, gender, comorbidities), initial (emergency service presentation) complete blood count parameters including WBC, MPV, CRP, procalcitonin levels. We also noted the hospitalisation unit (clinic/intensive care unit), hospitalisation length and the outcome.
We included all COVID-19 diagnosed and hospitalised patients in the study. The exclusion criterias were patients under 18 years old, cardiopulmonary arrest in the ED and the pregnants.

\section{Statistical ANAlyseS}

Statistical comparisons were performed using the statistical software package SPSS 23.0 (SPSS Inc., Chicago, IL, USA). KolgomogroSmirnow test used for normal distribution. For comparing parameters without normal distribution Student T-test, for parameters with normal distribution Mann Whitney U Test was used. Chi-Square test was used for comparing the categorical variables. Paired T test was used for continious variables. Definitive statistics were noted as "Mean \pm standart deviation (SD)" and "Median (interquartiles, IQR)". Significance level was 0.05 .

\section{RESULTS}

We included 16 females, 21 males totally 37 patients in this study. The mean age of the study group was 54.46. The detailed demographic data is given in table 1 .

Table1. Age and gender distribution of the study group

\begin{tabular}{|c|c|c|c|}
\hline \multicolumn{2}{|c|}{$\mathbf{N = 3 7}$} & $\mathbf{n}(\boldsymbol{\%})$, mean [SD] & \\
\hline \multicolumn{2}{|c|}{ Age } & $54.46[18,191]$ & $73.143[7.058]$ \\
& $\geq 65$ & $\mathrm{~N}=14(37.8 \%)$ & $43.087[12.438]$ \\
\hline \multirow{2}{*}{ Gender } & $<65$ & $\mathrm{~N}=23(62.2 \%)$ & \\
\cline { 2 - 5 } & Male & $\mathrm{N}=21(56.8 \%)$ & \\
\hline
\end{tabular}

Although MPV level was higher in patients over 65 years of age, there was no statistically significant difference between MPV, WBC,

CRP and procalcitonin in patients under 65 years of age and over ( $p>0.05)$ (Table 2).

Table2. MPV, WBC, CRP and Procalcitonin levels by age groups

\begin{tabular}{|c|c|c|c|c|}
\hline \multicolumn{2}{|c|}{ Variables } & \multirow{2}{*}{$\begin{array}{c}\text { Mean [SD] } \\
13.236[15.506] \\
\end{array}$} & \multirow{3}{*}{$\begin{array}{c}\text { MeanRank [SoR] } \\
-\end{array}$} & \multirow{3}{*}{$\frac{\text { p value }}{0.175}$} \\
\hline \multirow[t]{2}{*}{ MPV } & $\geq 65$ & & & \\
\hline & $<65$ & 8.783 [1.155] & & \\
\hline \multirow[t]{2}{*}{ WBC } & $\geq 65$ & & $17.54[245.5]$ & \multirow[t]{2}{*}{0.526} \\
\hline & $<65$ & & $19.89[457.5]$ & \\
\hline \multirow[t]{2}{*}{ CRP } & $\geq 65$ & & $22.71[318]$ & \multirow[t]{2}{*}{0.107} \\
\hline & $<65$ & & $16.74[385]$ & \\
\hline \multirow[t]{2}{*}{ Procalcitonin } & $\geq 65$ & & $22.96[321.5]$ & \multirow[t]{2}{*}{0.082} \\
\hline & $<65$ & & $16.59[381.5]$ & \\
\hline
\end{tabular}

Although MPV levels were higher in the patients who were followed up in the service than in the patients who were followed up in the intensive care unit, there was no statistically significant difference between MPV, WBC, CRP and procalcitonin levels in the patients followed in the service and intensive care unit (p>0.05) (Table 3). 
Is Mean Platelet Volume Useful for Predicting the Prognosis of COVID-19 Diagnosed Patients?

Table3. MPV, WBC, CRP and Procalcitonin levels according to intensive care unit and service admissions status

\begin{tabular}{|c|c|c|c|c|}
\hline \multicolumn{2}{|c|}{ Variables } & Mean [SD] & Mean Rank [SoR] & p value \\
\hline \multirow[t]{2}{*}{ MPV } & Service & $10.548[10.525]$ & \multirow[t]{2}{*}{-} & \multirow[t]{2}{*}{0.909} \\
\hline & Int. Care & $10.05[0.761]$ & & \\
\hline \multirow[t]{2}{*}{ WBC } & Service & & $17.63[546.5]$ & \multirow[t]{2}{*}{0.08} \\
\hline & Int. Care & & $26.08[156.5]$ & \\
\hline \multirow[t]{2}{*}{ CRP } & Service & & $17.58[545]$ & \multirow[t]{2}{*}{0.073} \\
\hline & Int. Care & & $26.33[158]$ & \\
\hline \multirow[t]{2}{*}{ Procalcitonin } & Service & & $18.02[558.5]$ & \multirow[t]{2}{*}{0.215} \\
\hline & Int. Care & & $24.08[144.5]$ & \\
\hline
\end{tabular}

Low MPV, high WBC, and procalcitonin levels were found to be associated with mortality, but no statistical difference was found ( $\mathrm{p}>0.05)$ (Table 4).

Table4. Relationship of MPV, WBC, CRP and Procalcitonin levels with mortality

\begin{tabular}{|c|c|c|c|c|}
\hline \multicolumn{2}{|c|}{ Variables } & Mean [SD] & MeanRank [SoR] & p value \\
\hline \multirow[t]{2}{*}{ MPV } & Discharged & $10.566[10.343]$ & \multirow[t]{2}{*}{-} & \multirow[t]{2}{*}{0.878} \\
\hline & Exitus & $9.84[1.482]$ & & \\
\hline \multirow[t]{2}{*}{ WBC } & Discharged & & $18.55[593.5]$ & \multirow[t]{2}{*}{0.531} \\
\hline & Exitus & & $21.9[109.5]$ & \\
\hline \multirow[t]{2}{*}{ CRP } & Discharged & & $17.69[566]$ & \multirow[t]{2}{*}{0.064} \\
\hline & Exitus & & $27.40[137]$ & \\
\hline \multirow[t]{2}{*}{ Prokalsitonin } & Discharged & & $18.33[558.5]$ & \multirow[t]{2}{*}{0.35} \\
\hline & Exitus & & $23.3[116.5]$ & \\
\hline
\end{tabular}

\section{DISCUSSION}

MPV count is used as a marker of the inflammatory response. Previous studies have shown a correlation between MPV and platelet function and activation. Inflammatory cytokines have been shown to reflect both prothrombotic and proinflammatory conditions by regulating thrombopoiesis and MPV. Large and small sized platelets in circulation are associated with the intensity of systemic inflammation (5).

COVID-19, which caused a serious pandemic effect in the world in 2020, is a viral infection that people have not encountered before. Numerous studies have been carried out quickly in order to have information about COVID-19. Studies showing the role of whole blood parameters in COVID-19 have been published. In a study by Guan et al. with 1099 COVID-19 patients, they found $80 \%$ lymphocytopenia, $36 \%$ thrombocytopenia and $33 \%$ leukopenia (7).

High MPV level has been shown to be associated with vascular thromboembolic and ischemic diseases. A study concluded that high MPV level may be a marker for the severity and prognosis of inflammation (8). However, in our study, no statistically significant difference was found between MPV levels and age group, mortality and service $(\mathrm{p}>0.05)$.
A study conducted in China in which 111 patients were taken by Zhang et al. showed that there was a correlation between WBC, CRP and procalcitonin levels and mortality in COVID-19 patients (9). A study in which 40 patients were taken by Liu et al. Showed a correlation between WBC and CRP levels and prognosis in COVID-19 patients (10). In meta-analysis published by Henry et al., they identified many variables for risk classification models that can be used as serious and deadly COVID-19 clinical indicators. They proposed close monitoring of WBC, Lymphocyte count, Platelet count, IL-6, ferritin and CRP levels in severe COVID-19 patients. They also suggested monitoring the procalcitonin levels for a second bacterial coinfection (11). However, in our study, no statistically significant difference was found between age groups and between mortality and WBC, CRP and procalcitonin levels $(\mathrm{p}>0.05)$.

\section{CONCLUSION}

We did not find a statistically significant difference in MPV levels, WBC, CRP and procalcitonin levels, mortality and prognosis in COVID-19 positive patients under 65 and over. Further comprehensive studies are required. 


\section{REFERENCES}

[1] World Health Organization. (2020). Naming the coronavirus disease (COVID-19) and the virus that causes it. World Health Organization. https://www. who. int/emergencies/ diseases/ novel-coronavirus-2019/technical-guidance/ naming-the-coronavirus-disease-(covid-2019)and-the-virus-that-causes-it

[2] W.G. Carlos, C.S. Dela Cruz, B. Cao, S. Pasnick, S. Jamil. Novel Wuhan (2019-nCoV) coronavirus Am J Respir Crit Care Med, 201 (2020), pp. P7-P8, 10.1164/rccm.2014P7.

[3] Paules CI, Marston HD, Fauci AS. Coronavirus infections-More than just the common cold. JAMA. 2020;323:707.

[4] Guan WJ, Ni ZY, Hu Y, et al. Clinical Characteristics of Coronavirus Disease 2019 in China. N Engl J Med 2020 Feb 28.

[5] YOLCU, Sadiye, et al. Can mean platelet volume levels of trauma patients predict severity of trauma?.Platelets, 2014, 25.4: 279-284.

[6] Conti, P., Ronconi, G., Caraffa, A., Gallenga, C. E., Ross, R., Frydas, I., \& Kritas, S. K. Induction of pro-inflammatory cytokines (IL-1 and IL-6) and lung inflammation by Coronavirus-19 (COVI-19 or SARS-CoV-2): anti-inflammatory strategies. Journal of biological regulators and homeostatic agents, 2020; 34(2).
[7] Guan, W. J., Ni, Z. Y., Hu, Y., Liang, W. H., $\mathrm{Ou}, \mathrm{C} . \mathrm{Q} ., \mathrm{He}$, J. X., ... \& Du, B. Clinical characteristics of coronavirus disease 2019 in China. New England journal of medicine, 382(18), 2020; 1708-1720.

[8] Baklac1, D., Guler, İ., Kuzucu, İ., Kum, R. O., \& Özcan, M. Status of Lactate Dehydrogenase, Neutrophil-lymphocyte Ratio, Mean Platelet Volume, and Platelet-lymphocyte Ratio in Bell's Palsy. Cureus, 2020; 12(3).

[9] Zhang, J., Yu, M., Tong, S., Liu, L. Y., \& Tang, L. V. Predictive factors for disease progression in hospitalized patients with Coronavirus Disease 2019 in Wuhan, China. Journal of Clinical Virology, 2020; 104392.

[10] Liu, J., Li, S., Liu, J., Liang, B., Wang, X., Wang, H., ... \& Xiong, L. Longitudinal characteristics of lymphocyte responses and cytokine profiles in the peripheral blood of SARS-CoV-2 infected patients. EBioMedicine, 2020; 102763.

[11] Henry, B. M., de Oliveira, M. H. S., Benoit, S., Plebani, M., \& Lippi, G. (2020). Hematologic, biochemical and immune biomarker abnormalities associated with severe illness and mortality in coronavirus disease 2019 (COVID19): a meta-analysis. Clinical Chemistry and Laboratory Medicine (CCLM), 2020; 1(aheadof-print).

Citation: Ahmet Aktaş et al, "Is Mean Platelet Volume Useful for Predicting the Prognosis of COVID-19 Diagnosed Patients?", International Journal of Research Studies in Medical and Health Sciences. 2020; 5(7): 08-11.

Copyright: (C) 2020 Ahmet Aktaş et al, This is an open-access article distributed under the terms of the Creative Commons Attribution License, which permits unrestricted use, distribution, and reproduction in any medium, provided the original author and source are credited. 